ORIGINAL PAPER

Luis E. Giraldo · Gregory J. Jennings

Willy Deleersnijder · Cecile Hamers-Casterman

Mark F. Wiser

\title{
Characterization of a Plasmodium chabaudi gene encoding a protein with glutamate-rich tandem repeats
}

Received: 3 March 1998 / Accepted: 7 July 1998

\begin{abstract}
Several highly antigenic proteins containing tandem repeats rich in glutamic acid residues have been described in Plasmodium falciparum. However, relatively little information is available about analogous genes in rodent parasites. This report describes a $4.2-\mathrm{kb}$ genomic DNA fragment from $P$. chabaudi with a deduced amino acid sequence that is predominantly glutamate-rich tandem repeats. Several different monoclonal antibodies raised against a $93-\mathrm{kDa} P$. chabaudi protein, which does not correspond to the cloned DNA fragment, recognize a recombinant protein expressed from the $4.2-\mathrm{kb}$ DNA fragment. The only sequence similarities between these two genes are tandem repeats with a predominance of glutamate pairs followed by a hydrophobic residue. This repetitious-sequence motif may be the basis for the observed cross-reactivity. A similar motif has been demonstrated to be the basis for antibody cross-reactivity between glutamate-rich proteins of $P$. falciparum. The expression of multiple glutamate-rich proteins with cross-reacting epitopes may be a general phenomenon in Plasmodium species.
\end{abstract}

L.E. Giraldo $^{1}$ · G.J. Jennings ${ }^{2}$ - M.F. Wiser $(\bowtie)$

Department of Tropical Medicine,

Tulane University School of Public Health,

1501 Canal Street,

New Orleans, LA 70112, USA

e-mail: wiser@mailhost.tcs.tulane.edu,

Fax: + 1-504-9886686

W. Deleersnijder ${ }^{3} \cdot$ C. Hamers-Casterman

Instituut voor Moleculaire Biologie,

Vrije Universiteit Brussel,

Brussels, Belgium

Present addresses:

${ }^{1}$ Corporacin Centro Internacional de Entrenamineto

e Investigaciones Medicas (CIDEIM), Cali, Colombia

${ }^{2}$ Michigan Department of Community Health,

P.O. Box 30035, Lansing, MI 48909, USA

${ }^{3}$ Innogenetics N.V., Industriepark Zwijnaarde 7,

B-9052 Zwijnaarde, Belgium

\section{Introduction}

The characterization of malarial antigens is an important step towards understanding anti-malarial immunity and developing a malaria vaccine. Several Plasmodium falciparum blood-stage antigens have been identified by screening recombinant DNA libraries with immune sera. Many of these antigens contain blocks of tandem repeats that are rich in glutamic acid residues. Examples of glutamate-rich blood-stage antigens included Pf155/RESA (Coppel et al. 1984), GLURP (Borre et al. 1991), MESA (Coppel 1992), Ag332 (Mattei and Scherf 1992), Pf11-1 (Scherf et al. 1992), and D260 (Barnes et al. 1995). These proteins are highly antigenic, but little is known about their biological functions or their roles in anti-malarial immunity. Furthermore, many of these glutamate-rich proteins exhibit cross-reacting epitopes (Mattei et al. 1989; Ahlborg et al. 1991; Wahlin et al. 1992). Although several glutamate-rich proteins have been described in $P$. falciparum, little work has been done on similar proteins in rodent malaria species. Phosphoproteins containing high levels of acidic residues have been identified on the host membrane of $P$. bergheiand $P$. chabaudi-infected erythrocytes (Wiser et al. 1988). The best characterized of these acidic phosphoproteins is a $93-\mathrm{kDa} P$. chabaudi protein called Pc(em)93. Several investigators have independently identified proteins referred to as Pch105/RESA, Pc96, and Pc90 which are now known to be homologues of Pc(em)93 (Holmquist et al. 1990; Wiser et al. 1997). Cloning and sequencing the $\mathrm{Pc}(\mathrm{em}) 93$ gene from three different $P$. chabaudi lines revealed tandem repeats rich in glutamic acid residues (Schmitt-Wrede et al. 1993; Wanidworanun et al. 1997; Giraldo et al. 1998). Although quite similar, the sequences of the tandem repeats vary between parasite lines. This report describes a distinct $P$. chabaudi gene encoding glutamate-rich tandem repeats which are recognized by monoclonal antibodies against $\mathrm{Pc}(\mathrm{em}) 93$. 


\section{Materials and methods}

\section{Parasites}

P. chabaudi chabaudi (strain 54X) was obtained from Dr. R. Walter (Bernhard Nocht Institut, Hamburg, Germany) and maintained by serial passage in CD1 outbred mice. Strain $54 \mathrm{X}$ was originally isolated by Dr. I. Landau (Landau and Killick-Kendrick 1966), acquired by Dr. P.I. Trigg (Trigg 1968) and then supplied to Dr. Walter. Mice were acquired from Charles Rivers Laboratories and maintained at the Tulane University Medical Center vivarium. Parasitemia was monitored by Giemsa-stained thin blood smears obtained from the tail. The IP-PC1 strain of $P$. chabaudi chabaudi was used in some of the studies and maintained as described elsewhere (Deleersnijder et al. 1992). Parasitized erythrocytes were passed over a CF-11 (Whatman) column and washed three times with Hanks' balanced-salts solution supplemented with $5 \mathrm{mM}$ HEPES, pH 7.4 and $0.25 \%$ glucose. The cells were washed once in K-1 buffer (Wiser and Schweiger 1985) and resuspended in 10-20 times the initial packed cell volume. Infected erythrocytes were lysed with $0.01 \%$ saponin at $37^{\circ} \mathrm{C}$ for 5 min and washed with $\mathrm{K}-1$ buffer until hemoglobin free. The packed parasites were either immediately extracted for DNA or were stored at $-75^{\circ} \mathrm{C}$ until use.

\section{Genomic DNA isolation}

Packed parasites were resuspended in 5-10 volumes of STE buffer (10 $\mathrm{m} M$ Tris, $\mathrm{pH} 8.0$, containing $0.1 \mathrm{M} \mathrm{NaCl}$ and $1 \mathrm{~m} M$ EDTA) containing $0.5 \%$ sodium dodecyl sulfate (SDS) and $0.1 \mathrm{mg} / \mathrm{ml}$ proteinase $\mathrm{K}$. Following a $2-\mathrm{h}$ incubation at $50{ }^{\circ} \mathrm{C}$, additional proteinase $\mathrm{K}(0.1 \mathrm{mg} / \mathrm{ml})$ was added and the incubation continued overnight. Insoluble material was removed by centrifugation and the lysate was extracted with an equal volume of saturated phenol for 4-16 h with gentle rocking. Genomic DNA (gDNA) was precipitated from the aqueous phase with 2.5 volumes of $100 \%$ ethanol $\left(-20{ }^{\circ} \mathrm{C}\right.$ and swirled out with a curved pasteur pipette). The gDNA was dissolved in STE buffer, treated with RNase A $(0.1 \mathrm{mg} /$ $\mathrm{ml}$ ) for $30 \mathrm{~min}$ at $37^{\circ} \mathrm{C}$ and subjected to another round of proteinase $\mathrm{K}$ digestion, phenol extraction, and ethanol precipitation. This final gDNA precipitant was dissolved in $0.5-1 \mathrm{ml}$ of $10 \mathrm{mM}$ Tris, $\mathrm{pH}$ 8.0, containing $1 \mathrm{~m} M$ EDTA, and stored at $4{ }^{\circ} \mathrm{C}$ until use. DNA concentration and quality were determined spectrophotometrically at 260 and $280 \mathrm{~nm}$. Only gDNA preparations with $\mathrm{A}_{260}$ / $\mathrm{A}_{280}$ ratios of $1.6-1.8$ were used.

\section{Southern blot analysis}

Ten micrograms of gDNA was digested in a volume of $100 \mu \mathrm{l}$ with 10-20 units of restriction enzyme using the recommended buffer. After $2 \mathrm{~h}$ of incubation, 10-20 additional units of restriction enzyme were added and the incubation continued overnight. The digested gDNA was precipitated and electrophoresed on $0.75-$ $0.8 \%$ agarose gels. After electrophoresis, the DNA was denatured by subjecting the gel to two 15 -min washes in a $0.5 M \mathrm{NaOH}$ plus 1.0 $\mathrm{M} \mathrm{NaCl}$ solution followed by neutralization with two $15-\mathrm{min}$ washes in $0.5 M$ Tris, pH 7.4, containing $1.5 M \mathrm{NaCl}$. DNA was transferred to nylon membranes (Micron Separation) using a Posiblot apparatus (Stratagene) and cross-linked to the membrane with ultraviolet radiation (BioRad, GS Gene Linker). A 2-h prehybridization was carried out at $42{ }^{\circ} \mathrm{C}$ in $6 \times \mathrm{SSC}$ solution $(15 \mathrm{mM}$ citrate, $\mathrm{pH} 7.0$, containing $0.15 \mathrm{M} \mathrm{NaCl}$ ) containing $5 \times$ Denhardt's reagent ( $1 \%$ Ficoll plus $1 \%$ polyvinylpyrrolidone plus $1 \%$ bovine serum albumin), $50 \%$ formamide, $0.2 \%$ SDS, and $100 \mu \mathrm{g} / \mathrm{ml}$ herring sperm DNA (Sigma). The ${ }^{32} \mathrm{P}$-labeled probe was added and hybridization carried out overnight at $42^{\circ} \mathrm{C}$ High-stringency washes were performed and the membranes exposed to X-ray film.

Radiolabeled probes were prepared from recombinant DNA inserts which were excised from plasmids with restriction enzymes and gel purified using the Gene Clean Kit (Bio 101). The inserts were labeled by random priming according to the manufacturer's instructions (US Biochemical). Briefly, 25-50 ng of insert DNA was labeled using $50 \mu \mathrm{Ci}$ of $\alpha-{ }^{32} \mathrm{P}$-dTTP (NEN) and the probe was separated from unincorporated nucleotides by centrifugation through a Bio-gel P2 (Bio-Rad) column equilibrated with $10 \mathrm{mM}$ Tris, $\mathrm{pH} 7.5$, containing $1 \mathrm{mM}$ EDTA.

Preparation and screening of gDNA libraries

A $\lambda$ gt1 1 expression library was prepared from P. chabaudi (IP-PC1 strain) gDNA digested with EcoRI under star conditions as previously described (Deleersnijder et al. 1992) and screened with monoclonal antibody (Mab)-43. Mab-43 was generated from a fusion of the NS0/U myeloma cell line with spleen cells from mice made hyperimmune by repeated $P$. chabaudi (strain IP-PC1) infection.

Genomic DNA from the 54X strain was digested with Pst I and electrophoresed. The region of the gel corresponding to approximately $4.2 \mathrm{~kb}$ was excised and the size-fractionated gDNA was purified using the Gene Clean Kit (Bio 101). The size-fractionated gDNA was ligated into the PstI site of pBSIIKS + (Stratagene). This library was screened by probing colony lifts with ${ }^{32} \mathrm{P}$-labeled P26-R6 insert DNA.

\section{DNA sequencing}

Sequencing was performed by the Sanger dideoxy chain termination method using the Sequenase 2.0 kit (USB). Progressive unidirectional deletion clones were prepared using controlled exonuclease III digestion and sequenced. Sequence data were analyzed and managed with either PCGENE software (Intelligenetics) or MacDNASIS software (Hitachi). The GenBank database was searched for similar sequences using the BLAST program (Altschul et al. 1990) via the National Center of Biotechnology Information e-mail server.

\section{Expression and immunoblotting of recombinant P26-R6}

The P26-R6 insert DNA from the $\lambda \mathrm{gt} 11$ clone was subcloned into pBSIIKS + and progressive unidirectional nested deletions prepared from the $3^{\prime}$-end of the gene. Escherichia coli (JM83 strain) transformed with the various recombinants was grown in Luria broth containing $50 \mu \mathrm{g} / \mathrm{ml}$ ampicillin until reaching an $\mathrm{A}_{600}$ of 0.5 . The expression of the P26-R6 insert is possibly due to sequences near the $5^{\prime}$-end of the clone which exhibit homologies to the -35 element and TATA box of E. coli (GenBank accession number L21713). Samples corresponding to $10^{8}$ bacteria were analyzed by SDS gel electrophoresis and immunoblotting as previously described (Wiser et al. 1997). The antibodies used in the immunoblotting were Mab-43 (described above), Mab-13.5 (Wiser et al. 1988), Mab-B7E10 (Gabriel et al. 1986), Mab-8F2 (Wanidworanum et al. 1987) and Mab-6C12 (Wanidworanum et al. 1987).

\section{Results and discussion}

Mab-43 recognizes an approximately $93-\mathrm{kDa} P$. chabaudi protein referred to as Pc(em)93 (Wiser et al. 1997). A $\lambda$ gt11 cDNA expression library was screened with Mab-43, and clone P26-R6, containing an EcoRI insert fragment of $2.1 \mathrm{~kb}$, was obtained. Analysis of $P$. chabaudi gDNA by Southern blotting indicated that P26-R6 hybridized to a 4.2-kb Pst I gDNA fragment. Screening a Pst I size-fractionated gDNA library with the P26-R6 probe resulted in the cloning of the $4.2-\mathrm{kb}$ fragment, 
which was designated as clone Pc4.2. The insert fragment from clone Pc4.2, P. chabaudi gDNA digested with $P s t \mathrm{I}$, and a sample of original size-fractionate gDNA were analyzed by Southern blotting on the same gel with the P26-R6 probe. All three hybridizing DNA fragments are the same size (data not shown); thus, no detectable recombination has occurred in clone Pc4.2.

The sequence of clone Pc4.2 exhibits a high degree of identity to clone P26-R6 (Fig. 1). Nucleotides 2-1412 of clone P26-R6 (GenBank accession number L21713) are identical to nucleotides 1508-2918 of clone Pc4.2 (GenBank accession number U35149) except for an adenine at nucleotide 1381 in clone P26-R6 versus a cytosine at nucleotide 2887 in clone Pc4.2. The guanine at nucleotide 1 in clone P26-R6 versus an adenine at nucleotide 1507 in clone Pc4.2 is likely explained by the recognition of AAATTC by EcoRI under star conditions (Polisky et al. 1975), and the subsequent conversion to GAATTC following ligation into the EcoRI site of $\lambda$ gt11. Nucleotides 1413-2112 of clone P26-R6 exhibit no homology to clone Pc4.2. The lack of homology in the 3'-region of clone P26-R6 suggests that clone P26-R6 may be the result of a cloning artifact. This supposition was tested by carrying out Southern blots with DNA probes derived from a unidirectional nested deletion mutant encompassing the $5^{\prime}$-region (ND10 probe) or derived from a $D r a \mathrm{I} / E c o$ RI fragment (DraI probe) corresponding to the $3^{\prime}$-region (Fig. 1). The ND10 probe and the DraI probe exhibit different hybridization patterns in that they recognize different restriction fragments (Fig. 2). In addition, there is a possible EcoRI star site (GAAGTC) beginning at nucleotide 1413 in clone P26-R6. The sequence alignments and Southern blots indicate that the P26-R6 insert DNA does not represent a contiguous piece of DNA in the $P$. chabaudi genome, but is the result of either a spurious ligation or an

Fig. 1 Schematic of clones P26-R6 and Pc4.2. Overlap between clone P26-R6 and clone Pc4.2 is indicated by the open area and the crosshatching shows nonhomologous sequence. Stop codons are found throughout the nonhomologous sequence in all three reading frames and the asterisk denotes the position of the first in-frame stop codon. The thick lines denote the regions corresponding to a unidirectional nested deletion mutant (ND10 probe) and a DraI/EcoRI fragment (DraI probe) which are used as probes in Southern blotting (Fig. 2). Three distinct blocks of tandem repeats, designated $R 1, R 2$, and $R 3$, are observed in clone Pc4.2. A single open reading frame beginning at nucleotide 24 (orf) and continuing throughout clone Pc4.2 is observed. The positions of an in-frame ATG at nucleotide 81 (atg), three potential splice acceptor sites $(a c)$, and some relevant restriction sites are denoted

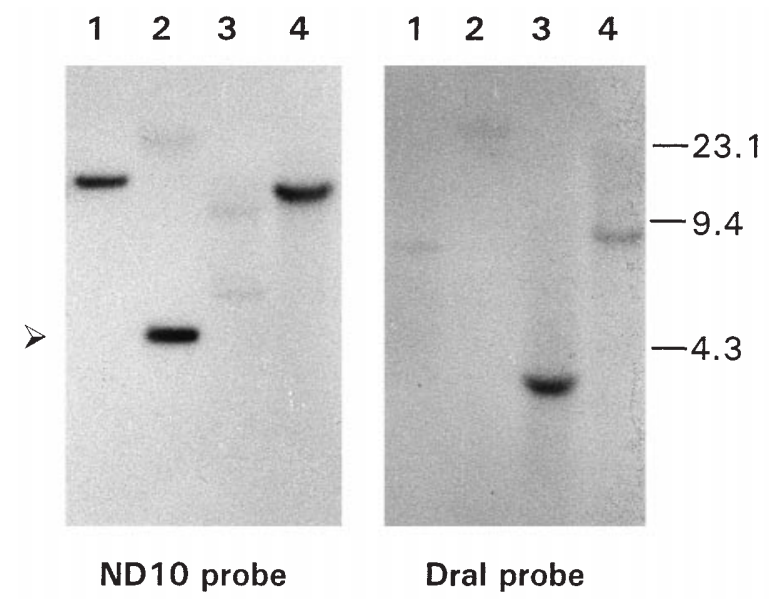

Fig. 2 Southern blot analysis. Plasmodium chabaudi gDNA was digested with Hind III (lanes 1), PstI (lanes 2), NsiI (lanes 3), and EcoRI (lanes 4) and electrophoresed as duplicate samples on the same gel. After electrophoresis, the DNA was transferred to a nylon membrane, and the duplicate blots were probed with either the ND10 or the DraI probes (Fig. 1) as indicated. The arrowhead denotes the position of the 4.2-kb PstI fragment (lane 2)

anomalous recombination. The nearly perfect identity between the overlapping regions of the two recombinant DNA clones is not unexpected since the IP-PC1 line was derived from the 54X line (Coombs and Gutteridge 1975; David et al. 1978) the respective sources of clones P26-R6 and Pc4.2.

Clone Pc4.2 contains a single open reading frame (ORF) beginning at nucleotide 24 and continuing throughout the remainder of the sequence (Fig. 1), indicating that clone Pc4.2 is missing the $3^{\prime}$-end of the gene. Regarding the $5^{\prime}$-end of the gene, the first in-frame initiation codon is at nucleotide 81 . This ATG does not have the characteristics of other Plasmodium start codons since it lacks adenines at positions -1 and -3 (Saul and Battistutta 1990; Robson and Jennings 1991). Furthermore, no typical eukaryotic promoter elements, such as TATA boxes or CAP sites, are detected upstream of this ATG. Other in-frame methionines (positions 1065, 1239, and 1375) are within the tandem repeats and therefore probably do not represent start codons. Splice junctions and branch points of Plasmodium introns are conserved with other eukaryotes (Brown and Coppel, 1991) and several potential splice acceptor sequences are observed at nucleotides 191-192, 332-333, 383-384, 426-427, and 440-441 (Fig. 1). However, no potential splice donor sequences are found. The sequence data are

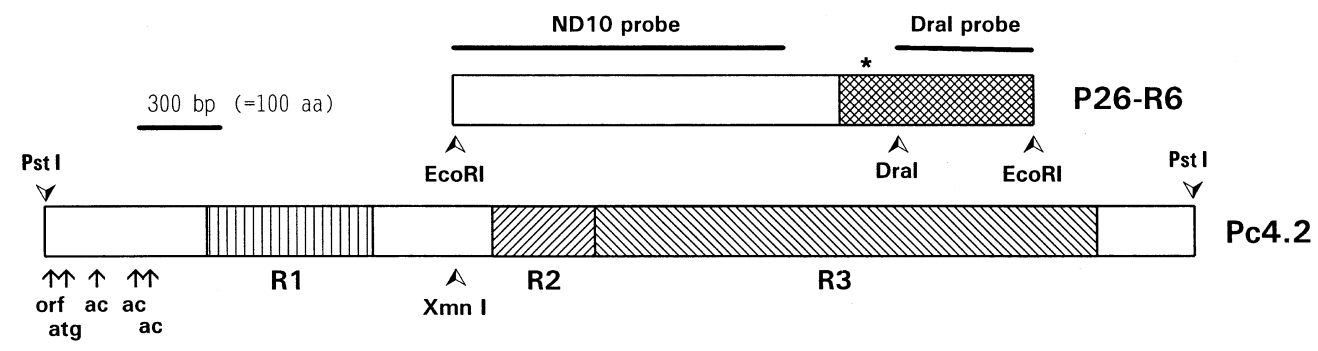


most consistent with the $5^{\prime}$-end of clone Pc4.2 being within an intron and the presumptive splice donor being upstream of the $5^{\prime}$-PstI restriction site.

The ORF of clone Pc4.2 encodes $159 \mathrm{kDa}$ of a protein with particularly high levels of glutamate $(14.6 \%)$, asparagine $(11.5 \%)$ and isoleucine $(10.5 \%)$. Approximately $80 \%$ of the Pc4.2 sequence is composed of three distinct blocks of tandem repeats (Figs 1, 3). Repeat block one (R1) contains five tandem repeats of either 38 or 33 amino acids and one partial copy of the repeat. Repeat block two (R2) contains five degenerate repeats of 25 amino acids and repeat block three (R3) contains 26 tandem repeats of 24 or 25 amino acids interrupted twice by a related 14-amino-acid sequence. The R2 and $\mathrm{R} 3$ repeats are contiguous and exhibit partial homology. All of the repeat blocks contain highly conserved glutamate residues throughout the respective repeats. Interestingly, some of these glutamates in the R2 and R3 repeats are spaced so that a glutamate residue occurs every 11-13 amino acids throughout the entire repeat block with only three exceptions (Fig. 3).

Clone Pc4.2 exhibits little homology to Pc(em)93 sequences (GenBank accession numbers L01040, U58989, and U80896) even though it was isolated as a result of screening expression libraries with an anti-Pc(em)93

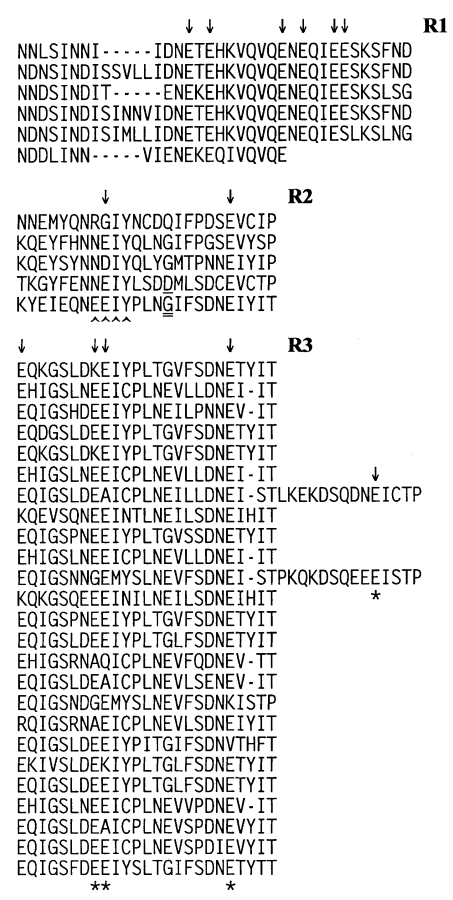

Fig. 3 Deduced amino acid sequence of Pc4.2 tandem repeats. The deduced amino acid sequence of repeat block one $(R l)$, repeat block two $(R 2)$, and repeat block three $(R 3)$ is shown. The arrows denote highly conserved glutamate residues within the repeats and the asterisks are below glutamates that are evenly spaced every 11-13 amino acids. The underlined residue denotes the last amino acid of a unidirectional nested deletion mutant which does not express a protein recognized by Mab-13.5. The double underline denotes the last residue of the smallest nested deletion mutant which expresses a protein recognized by Mab-13.5. The ^^^^ denote an EEIY sequence within this 25 -amino-acid region which is conserved in the R3 block
Mab. The validity of the $\mathrm{Pc}(\mathrm{em}) 93$ clones has been corroborated (Giraldo et al. 1998). Furthermore, the size of the clone Pc4.2 ORF, which is probably still missing sequence from both ends, is too large to be $\mathrm{Pc}(\mathrm{em}) 93$. Therefore, clone Pc4.2 is not the gene for $\mathrm{Pc}(\mathrm{em}) 93$ but represents another glutamate-rich protein which is recognized by Mab-43. Other anti-Pc(em)93 Mabs have also been tested for reactivity against clone P26-R6. Mab-13.5 and Mab-6C12 react with clone P26-R6, whereas Mab-8F2 and Mab-B7E10 do not (Table 1). Clone P26-R6 expresses 37 amino acids at the C-terminus which are not part of the clone Pc4.2 sequence (Fig. 1). It is unlikely, though, that the observed crossreactivity is due to recognition of these 37 amino acids since absolutely no homology nor similarity is observed between these residues and the $\mathrm{Pc}(\mathrm{em}) 93$ sequence (data not shown). However, the tandem repeats of clone Pc4.2 and $\mathrm{Pc}(\mathrm{em}) 93$ do exhibit similarities (see below) suggesting that the cross-reactivity is due to the glutamaterich tandem repeats.

The cross-reactivity of these Mabs extends to other malarial proteins. For example, screening an expression library with Mab-B7E10 resulted in the cloning of clone Pch105e (Snounou et al. 1988) which also reacts with some of the other anti-Pc(em)93 Mabs (Holmquist et al. 1990). The sequence of clone Pch 105 e (GenBank accession number AF019972) is not homologous to either $\mathrm{Pc}(\mathrm{em}) 93$ or clone Pc4.2, but encodes yet another protein rich in asparagine $(16.2 \%)$ and glutamate $(13.1 \%)$. In addition, some of the anti-Pc(em)93 Mabs are known to recognize proteins from other Plasmodium species. For example, Mab-B7E10 (Holmquist et al. 1988) and Mab-7C6 (Wanidworanum et al. 1989) cross-react with Pf155/RESA, and Mab-7C6 recognizes proteins from $P$. vivax and $P$. cynomolgi (Wanidworanum et al. 1989).

Searching databases with the Pc4.2 nucleotide and deduced protein sequences did not reveal any highly homologous sequences; thus, Pc4.2 represents a previously undescribed gene. A limited amount of similarity, however, is observed between Pc4.2 and several different $P$. falciparum glutamate-rich and/or asparagine-rich proteins, with Ag332 (Mattei and Scherf, 1992) and MESA (Coppel 1992) being the most notable. The

Table 1 Reactivities of anti-Pc(em) 93 monoclonal antibodies with non-Pc(em)93 recombinant DNA clones. Line indicates the Plasmodium chabaudi line used to generate the Mab (Pca P. c. adami). Escherichia coli expressing clone P26-R6 were analyzed by immunoblotting with the indicated Mab. The reactivity against clone Pch105e was derived from Holmquist et al. (1990) (nd not determined)

\begin{tabular}{llcc}
\hline Mab & Line & \multicolumn{2}{c}{ Recombinant DNA Clone } \\
\cline { 3 - 4 } & & Pc26-R6 & Pch105e \\
\hline 13.5 & $54 \mathrm{X}$ & + & $\mathrm{nd}$ \\
43 & IP-PC1 & + & + \\
B7E10 & AS & - & + \\
8 F2 & Pca & - & - \\
$6 \mathrm{C} 12$ & Pca & + & nd \\
\hline
\end{tabular}


similarities between the deduced Pc4.2 sequence and the sequences of Ag332 and MESA are due to resemblances in the tandem-repeat sequences. In particular, the tandem repeats of Ag332 and MESA both have numerous glutamate pairs followed by hydrophobic residues (e.g., EEV and EEI). The EEI motif is also found throughout the R3 repeats of Pc4.2 (Fig. 3). Antibodies against glutamate-rich proteins from $P$. falciparum often crossreact with other antigens. For example, Mab-33G2 primarily recognizes Ag332, but cross-reacts with Pf11.1 and Pf155/RESA (Mattei et al. 1989). The optimal epitope recognized by Mab-33G2 is VTEEI with the pair of glutamates followed by a hydrophobic residue being particularly important (Ahlborg et al. 1991). Similar motifs are found in the repeats of Ag332, Pf11.1, and Pf155/RESA, accounting for the cross-reactivity of Mab-33G2.

Unidirectional deletion mutants prepared from the 3 '-end of clone P26-R6 were used to map the epitope recognized by Mab-13.5. Immunoblotting of E. coli expressing the nested deletion mutants demonstrated that the last residue of the smallest nested deletion recognized by Mab-13.5 is a glycine in the last repeat in the R2 block (Fig. 3). The last residue in the largest nested deletion not expressing an epitope recognized by Mab-13.5 is an aspartate in the preceding repeat. Therefore, the epitope recognized by Mab-13.5 is mapped to a 24amino-acid region between the aspartate and glycine. The most striking sequence within this 24-amino-acid region is the EEIY, which is conserved throughout the R3 repeats and is similar to the EEIV and EENY sequences found in the repeats of the Pc(em)93 (Giraldo et al. 1998). These tetrapeptide sequences are similar to the sequences responsible for the cross-reactivity of antibodies with different $P$. falciparum glutamate-rich proteins with tandem repeats discussed above. Although the epitopes recognized by Mab-13.5 and the other P. chabaudi-specific Mabs have not been precisely mapped, it is plausible that the glutamate pairs in association with hydrophobic residues contribute to the antibody crossreactivities.

In summary, several $P$. falciparum proteins containing tandem repeats rich in glutamic acids have been described. Relatively few proteins with similar properties are known in other Plasmodium species. This report describes a previously unreported $P$. chabaudi gene that contains tandem repeats particularly rich in glutamic acid and asparagine. As also observed in the $P$. falciparum glutamate-rich proteins, the deduced amino acid sequence of this protein contains pairs of glutamates followed by a hydrophobic residue. This motif appears to be the basis for the cross-reacting determinants with other glutamate-rich proteins. Therefore, the expression of numerous proteins with glutamate-rich tandem repeats that exhibit cross-reacting epitopes may be a general feature of Plasmodium species. The functions of these glutamate-rich proteins are not known, but have been speculated to divert the immune system or serve as a 'smokescreen' (Anders 1986). In other cases, such as MESA (Coppel 1992) and Pc(em)93 (Giraldo et al. 1998), the proteins have been proposed to play a structural role in the modification of the host erythrocyte membrane.

Acknowledgement We gratefully acknowledge the excellent technical assistance of Maryetta Brooks and the financial support of NIH (grant AI31083). We also thank Drs. Chingchai Wanidworanum and Hanna Shear for providing Mab-6C12 and Mab8 F2. Portions of this research were carried out by L.E.G. in partial fulfill of the Ph.D. requirements from Tulane University.

\section{References}

Ahlborg N, Berzins K, Perlmann P (1991) Definition of the epitope recognized by the Plasmodium falciparum-reactive human monoclonal antibody 33G2. Mol Biochem Parasitol 46: 89-96

Altschul SF, Gish W, Miller W, Myers EW, Lipman DJ (1990) Basic local alignment search tool. J Mol Biol 215: 403-410

Anders RF (1986) Multiple cross-reactivities amongst antigens of Plasmodium falciparum impair the development of protective immunity against malaria. Parasite Immunol 8: 529-539

Barnes DA, Wollish W, Nelson RG, Leech JH, Petersen C (1995) Plasmodium falciparum: D260, an intraerythrocytic parasite protein, is a member of the glutamic acid dipeptide-repeat family of proteins. Exp Parasitol 81: 79-89

Borre MB, Dziegiel M, Hogh B, Petersen E, Rieneck K, Riley E, Meis JF, Aikawa M, Nakamura K, Harada M, Wind A, Jakobsen PH, Cowland J, Jepsen S, Axelsen NH, Vuust J (1991) Primary structure and localization of a conserved immunogenic Plasmodium falciparum glutamate rich protein (GLURP) expressed in both the preerythrocytic and erythrocytic stages of the vertebrate life cycle. Mol Biochem Parasitol 49: 119-131

Brown HJ, Coppel RL (1991) Primary structure of a Plasmodium falciparum rhoptry antigen. Mol Biochem Parasitol 49: 99-110

Coombs GH, Gutteridge WE (1975) Growth in vitro and metabolism of Plasmodium vinckei chabaudi. J Protozool 22: 555-560

Coppel RL (1992) Repeat structures in a Plasmodium falciparum protein (MESA) that binds to human erythrocyte protein 4.1. Mol Biochem Parasitol 50: 335-347

Coppel RL, Cowman AF, Anders RF, Bianco AC, Saint RB, Lingelbach KR, Kemp DJ, Brown GV (1984) Immune sera recognize an erythrocyte Plasmodium falciparum antigen composed of repeated amino acid sequences. Nature 310: 789-792

David PH, Hommel M, Benichou JC, Eisen HA, Pereira da Silva LH (1978) Isolation of malaria merozoites: release of Plasmodium chabaudi merozoites from schizonts bound to immobolized concanavalin A. Proc Natl Acad Sci USA 75: 5081-5084

Deleersnijder W, Prasomsitti P, Tungpradubkul S, Hendrix D, Hamers-Casterman C, Hamers R (1992) Structure of a Plasmodium chabaudi acidic phosphoprotein that is associated with the host erythrocyte membrane. Mol Biochem Parasitol 56: 59-68

Gabriel JA, Holmquist G, Perlmann H, Berzins K, Wigzell H, Perlmann P (1986) Identification of a Plasmodium chabaudi antigen present in the membrane of ring stage infected erythrocytes. Mol Biochem Parasitol 20: 67-75

Giraldo LE, Grab DJ, Wiser MF (1998) Molecular characterization of a Plasmodium chabaudi erythrocyte membrane associated protein with glutamate-rich tandem repeats. J Euk Microbiol, 45: 522-528

Holmquist G, Udomsangpetch R, Berzins K, Wigzell H, Perlmann P (1988) Plasmodium chabaudi antigen Pch105, Plasmodium falciparum antigen Pf155, and erythrocyte band 3 share crossreactive epitopes. Infect Immun 56: 1545-1550

Holmquist G, Nagasawa N, Berzins K, Snounou G, Viriyakosol S, Aikawa M, Wigzell H, Perlmann P (1990) Plasmodium chabaudi: polymorphic and nonpolymorphic epitopes of the antigen Pch105/RESA. Exp Parasitol 70: 436-442 
Landau I, Killick-Kendrick R (1966) Rodent plasmodia of the République Centrafricaine: the sporogony and tissue stages of Plasmodium chabaudi and P. berghei yoelii. Trans R Soc Trop Med Hyg 60: 633-649

Mattei D, Scherf A (1992) The Pf332 gene of Plasmodium falciparum codes for a giant protein that is translocated from the parasite to the membrane of infected erythrocytes. Gene 110: 71-79

Mattei D, Berzins K, Wahlgren M, Udomsangpeteh R, Perlmann P, Griesses HW, Scherf A, Muller-Hill B, Bonnefoy S, Guillotte M, Langsley G, Pereira da Silva L, Mercereau-Puijalon O (1989) Cross-reactive antigenic determinants present on different Plasmodium falciparum blood-stage antigens. Parasite Immunol 11: $15-30$

Polisky B, Greene P, Garfin DE, McCarthy BJ, Goodman HM, Boyer HW (1975) Specificity of substrate recognition by the EcoRI restriction endonuclease. Proc Natl Acad Sci USA 72: $3310-3314$

Robson KJH, Jennings MW (1991) The structure of the calmodulin gene of Plasmodium falciparum. Mol Biochem Parasitol 46: $19-34$

Saul A, Battistutta D (1990) Analysis of the sequences flanking the translational start sites of Plasmodium falciparum. Mol Biochem Parasitol 42: 55-62

Scherf A, Carter R, Petersen C, Alano P, Nelson R, Aikawa M, Mattei D, Dasilva LP, Leech J (1992) Gene inactivation of Pf11-1 of Plasmodium-falciparum by chromosome breakage and healing - identification of a gametocyte-specific protein with a potential role in gametogenesis. EMBO J 11: 2293-2301

Schmitt-Wrede HP, Qiao ZD, Wunderlich F (1993) A cDNA putatively encoding the Pc90-erythrocyte membrane antigen of Plasmodium chabaudi. Parasitol Res 79: 80-81
Snounou G, Viriyakosol S, Holmquist G, Berzins K, Perlmann P, Brown KN (1988) Cloning of genomic fragment from Plasmodium chabaudi expressing a 105 kilodalton antigen epitope. Mol Biochem Parasitol 28: 153-162

Trigg PI (1968) A new continuous perfusion technique for the cultivation of malaria parasites in vitro. Trans R Soc Trop Med Hyg 62: 371-378

Wahlin B, Sjolander A, Ahlborg N, Udomsangpetch R, Scherf A, Mattei D, Berzins K, Perlmann P (1992) Involvement of Pf155/ RESA and cross-reactive antigens in Plasmodium-falciparum merozoite invasion in vitro. Infect Immun 60: 443-449

Wanidworanum C, Barnwell JW, Shear HL (1987) Protective antigen in the membranes of mouse erythrocytes infected with Plasmodium chabaudi. Mol Biochem Parasitol 25: 195-201

Wanidworanum C, Barnwell JW, Nagasawa H, Aikawa M, Shear HL (1989) Crossreacting antigens to Pc96, a protective antigen of Plasmodium chabaudi, in P. falciparum, P. vivax and P. cynomolgi. Am J Trop Med Hyg 40: 579-584

Wanidworanun C, Levy DD, Shear HL (1997) Plasmodium chabaudi: cDNA of Pc96, a protective antigen associated with the erythrocyte membrane of infected erythrocytes. Exp Parasitol 85: $92-98$

Wiser MF, Schweiger HG (1985) Cytosolic protein kinase activity associated with the maturation of the malaria parasite Plasmodium berghei. Mol Biochem Parasitol 17: 179-189

Wiser MF, Leible MB, Plitt B (1988) Acidic phosphoproteins associated with the host erythrocyte membrane of erythrocytes infected with Plasmodium berghei and P. chabaudi. Mol Biochem Parasitol 27: 11-22

Wiser MF, Giraldo LE, Schmitt-Wrede HP, Wunderlich F (1997) Plasmodium chabaudi: immunogenicity of a highly antigenic glutamate-rich protein. Exp Parasitol 85: 43-54 